\title{
EARTHQUAKE RESISTANCE OF REINFORCED CONCRETE CORNER BEAM-COLUMN JOINTS WITH DIFFERENT COLUMN AXIAL LOADS UNDER BI- DIRECTIONAL LATERAL LOADING
}

\author{
Kazuhiro Kitayama ${ }^{1}$ and Hiromu Katae ${ }^{2}$
}

\author{
(Submitted February 2017; Reviewed May 2017; Accepted June 2017)
}

\begin{abstract}
The seismic performance of a corner beam-column joint in reinforced concrete frames was studied by testing two three-dimensional corner beam-column subassemblage specimens without slabs under constant column axial load and bi-directional lateral cyclic load reversals. The column-to-beam flexural strength ratio was varied from 1.4 to 2.3 by changing the magnitude of column axial load. Although a sufficient margin to prevent shear failure was provided to a corner beam-column joint in the test, the subassemblage specimens failed in joint hinging after beam and column longitudinal bars and joint hoops yielded. The ultimate joint hinging capacity of a corner joint under bi-directional lateral loading was enhanced by an increase in column compressive axial load, and can be estimated based on the new mechanism proposed by Kusuhara and Shiohara.
\end{abstract}

\section{INTRODUCTION}

A new mechanism of joint hinging was proposed by Shiohara [1], a professor at the University of Tokyo, Japan, for a beamcolumn joint in reinforced concrete (RC) moment-resisting frames. The joint hinging mechanism is observed in laboratory tests when an ultimate flexural capacity of a column section is close to that of a beam section in an RC unit frame. A joint hinging model proposed by Kusuhara and Shiohara [2] is shown in Figure 1 for a plane exterior beam-column joint. An exterior beam-column subassemblage is divided into three elements; an upper column, a lower column and a beam. Each element rotates like a rigid body as shown in Figure 1, forming a principal diagonal crack along a diagonal compression strut in a joint and a short diagonal crack developing from a reentrant corner in a tesion side.

Recent experimental studies to verify the joint hinging mechanism have been conducted using 2D plane interior [3] and exterior [4] beam-column subassemblage specimens. There are, however, few tests which use 3D beam-columnjoint subassemblages with orthogonal beams to each other which frame into a column such as a corner beam-column joint [5]. The previous study [5] dealt with not joint hinging failure, but beam flexural yielding. For corner columns in RC buildings, a loss of capacity to sustain column axial load resulting from severe damage to a corner joint has resulted in partial story collapse of the buildings in past earthquakes as illustrated in Figure 2 for the 1993 Guam Island Earthquake. The ultimate flexural capacity of a corner column frequently decreases during an earthquake because the axial load on the corner column cyclically increases and decreases by change of direction of lateral loads induced by earthquake excitations. Therefore, it is of great importance to investigate earthquake resistant performance of a corner beam-column joint subjected to tri-directional earthquake loading.

Therefore the seismic performance of a corner beam-column joint in RC frames was studied, focusing on joint hinging mechanism, by testing two three-dimensional beam-column subassemblage specimens without slabs under both constant column axial load and bi-directional lateral cyclic load reversals.

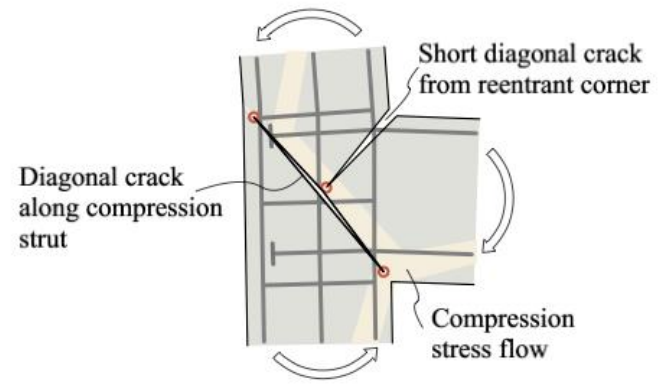

Figure 1: Joint hinging model for an exterior joint [2].

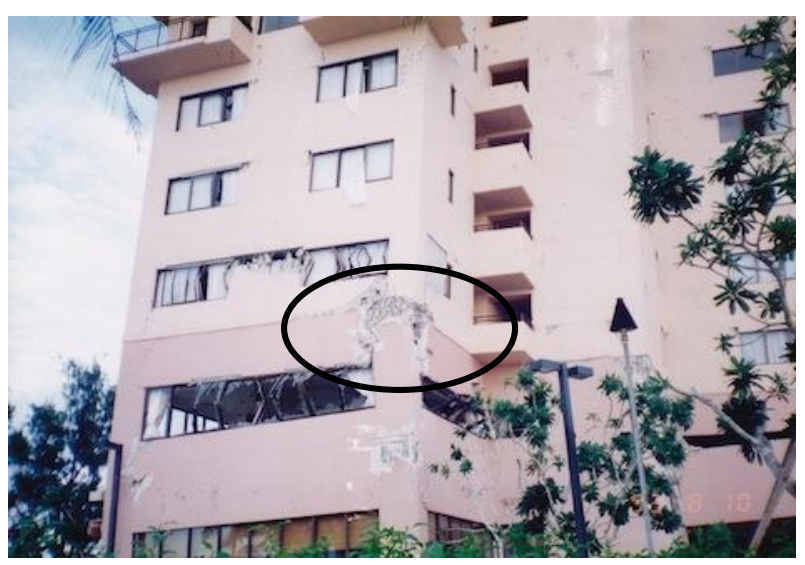

Figure 2: Failure of corner beam-column joint in Guam Island Earthquake in 1993. 


\section{OUTLINE OF TEST}

\section{Specimens}

Two half-scale 3D corner beam-column subassemblage specimens without slabs, removed from a 3D frame by cutting off the beams and columns at arbitrarily assumed inflection points, were tested. A configuration of specimens, section dimensions and reinforcement details are shown in Figure 3. Properties of specimens and material properties of concrete and steel are listed in Table 1 and 2 respectively. The length from a center of the column to a support of the beam end was $1600 \mathrm{~mm}$. The height from a center of the beam to the loading point at the top of the column or to the bottom support was $1200 \mathrm{~mm}$ respectively.

Section dimensions and reinforcement arrangement for beams and columns were consistent in the two specimens. The column had a square cross section of $350 \mathrm{~mm}$ width with longitudinal bars consisting of 8-D13(SD295A) and hoops of 2-D10(SD345) at a center-to-center spacing of $100 \mathrm{~mm}$. The beam had width of $250 \mathrm{~mm}$ and depth of $400 \mathrm{~mm}$ with longitudinal bars consisting of 4-D19(SD345) at the top and bottom of the section and stirrups of 2-D13(SD345) at a center-to-center spacing of $100 \mathrm{~mm}$. A ratio of the total amount of column longitudinal bars to a column gross sectional area was $0.83 \%$, and a joint-hoop-ratio was $0.28 \%$, which almost corresponded to the lower bound required by Japanese Building Standard Law or seismic provisions. Beam longitudinal reinforcement was mechanically anchored by an end plate, using a headed bar, within the joint core concrete with a horizontally projected length of $300 \mathrm{~mm}$ corresponding to 0.86 times the column depth. Concrete compressive strength was approximately $50 \mathrm{~N} / \mathrm{mm}^{2}$.

The magnitude of column compressive axial load was chosen as a test parameter; e.g., $260 \mathrm{kN}$ corresponding to a column axial stress ratio of 0.04 for Specimen $\mathrm{K} 2$ and $770 \mathrm{kN}$ corresponding to the ratio of 0.12 for Specimen K3. The change in column flexural strength was achieved by changing the magnitude of column compressive axial load. Here, the column-to-beam flexural strength ratio indicated in Table 1 was defined as a ratio of ultimate flexural strength of a column section to that of a beam section, which were computed by section analyses assuming that plane sections remain plane. The column-to-beam flexural strength ratio for specimens varied depending on the direction of lateral load due to the asymmetrical position of beam bars in a beam section and varying axial load in a lower column which was caused by change of a direction of beam shear force. Thus, the columnto-beam flexural strength ratio ranged from 0.8 to 1.6 for Specimen K2 and from 1.5 to 2.7 for Specimen K3 as shown in Figure 4; where, the column-to-beam flexural strength ratio under bi-directional loading was computed on the assumption that a surface of ultimate flexural strength of a column is circular, and beam ultimate flexural strength is taken as resultant flexural strength of two orthogonal beams. Figure 4 shows column-to-beam flexural strength ratios under eight loading directions, as pointed by arrows, at a top of the upper column. Hereafter, a column-to-beam flexural strength ratio of 1.4 for Specimen K2 and 2.3 for Specimen K3 under unidirectional loading towards the west direction is used respectively as a typical value of the ratio in the paper.
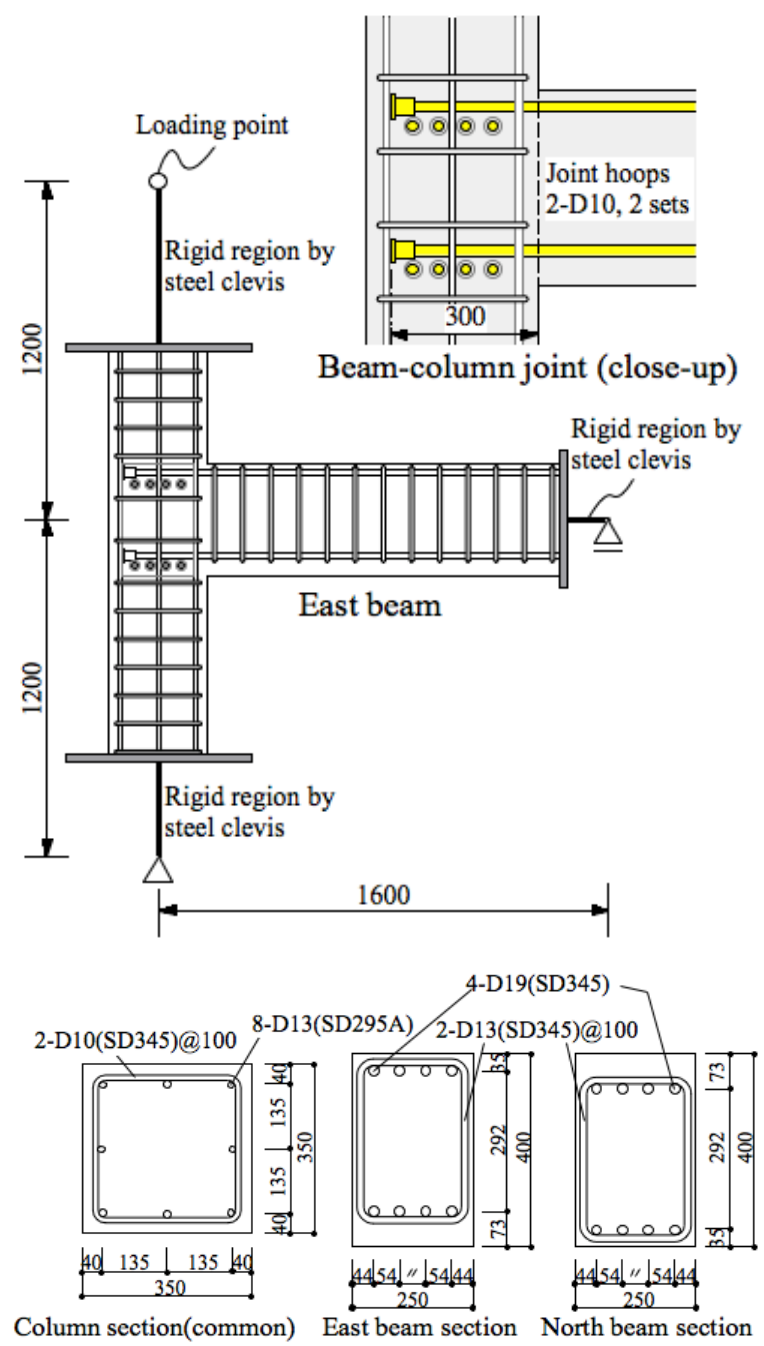

Figure 3: Details of specimens.

A joint shear redundancy ratio of 1.6 was provided to the corner beam-column joint in the test to prevent joint shear failure; where the joint shear redundancy ratio is defined as a ratio of an ultimate joint shear strength to the horizontal joint shear force introduced by tensile yielding force of the longitudinal bars in the beam. The ultimate joint shear strength $V_{\text {ju }}$ was estimated according to Architectural Institute of Japan (AIJ) provisions [6] as indicated below.

$V_{j u}=\left(\kappa \cdot \varphi \cdot F_{j}\right) b_{j} D_{j}$

where $\kappa$ : shape factor of a joint equal to 1.0 for an interior joint, 0.7 for an exterior joint and 0.4 for a knee joint, $\phi$ : correction factor for the effect of transverse beams equal to 1.0 for a joint with transverse beams on both sides and 0.85 for other types of a joint, $F_{\mathrm{j}}$ : standard value of an ultimate joint shear strength expressed as follows, where $f_{\mathrm{c}}$ ' : concrete compressive strength (unit in $\mathrm{N} / \mathrm{mm}^{2}$ );

$F_{j}=0.8 \cdot f_{c}^{\prime 0.7} \quad$ [unit in $\mathrm{N} / \mathrm{mm}^{2}$ ] 
Table 1: Properties of specimens.

\begin{tabular}{|c|c|c|c|}
\hline \multicolumn{2}{|l|}{ Specimen } & $\mathrm{K} 2$ & $\mathrm{~K} 3$ \\
\hline \multirow{3}{*}{ East and North beams } & Width x Depth & \multicolumn{2}{|c|}{$250 \times 400 \mathrm{~mm}$} \\
\hline & Longitudinal bars & \multicolumn{2}{|c|}{ Top and Bottom ; 4-D19 } \\
\hline & Stirrups & \multicolumn{2}{|c|}{ 2-D13(SD345)@100 } \\
\hline \multirow{3}{*}{ Column } & Width x Depth & \multicolumn{2}{|c|}{$350 \times 350 \mathrm{~mm}$} \\
\hline & Longitudinal bars & \multicolumn{2}{|c|}{ 8-D13(SD295A) } \\
\hline & Hoops & \multicolumn{2}{|c|}{ 2-D10@100 } \\
\hline \multicolumn{2}{|c|}{ Joint hoops (reinforcement ratio $; p_{\mathrm{jw}}$ ) } & \multicolumn{2}{|c|}{ 2-D10, 2 sets $(0.28 \%)$} \\
\hline \multicolumn{2}{|c|}{ Column axial load (axial stress ratio) } & $260 \mathrm{kN}(0.04)$ & $770 \mathrm{kN}(0.12)$ \\
\hline \multirow{2}{*}{$\begin{array}{l}\text { Story shear force at ultimate beam flexural } \\
\text { capacity (predicted) }\end{array}$} & Max. & $74.9 \mathrm{kN}$ & $75.9 \mathrm{kN}$ \\
\hline & Min. & $64.9 \mathrm{kN}$ & $65.1 \mathrm{kN}$ \\
\hline \multirow{2}{*}{$\begin{array}{l}\text { Story shear force at joint hinging capacity } \\
\text { (predicted) }\end{array}$} & Max. & $70.4 \mathrm{kN}$ & $88.7 \mathrm{kN}$ \\
\hline & Min. & $60.0 \mathrm{kN}$ & $82.0 \mathrm{kN}$ \\
\hline \multirow{2}{*}{ Column-to-beam flexural strength ratio } & Max. & 1.6 & 2.7 \\
\hline & Min. & 0.8 & 1.5 \\
\hline \multirow{2}{*}{ Joint shear redundancy ratio } & under uni-directional loading & \multicolumn{2}{|c|}{1.6} \\
\hline & under bi-directional loading & \multicolumn{2}{|c|}{1.1} \\
\hline
\end{tabular}

* Ultimate capacities vary depending on loading directions.

Table 2: Properties of materials.

\begin{tabular}{l|c|c|c|c}
\hline (a) Steel & $\begin{array}{c}\text { Yield } \\
\text { strength } \\
\mathrm{N} / \mathrm{mm}^{2}\end{array}$ & $\begin{array}{c}\text { Ultimate } \\
\text { tensile } \\
\text { strength } \\
\mathrm{N} / \mathrm{mm}^{2}\end{array}$ & $\begin{array}{c}\text { Yield } \\
\text { strain } \\
\%\end{array}$ & $\begin{array}{c}\text { Fracture } \\
\text { strain } \\
\%\end{array}$ \\
\hline $\mathrm{D} 10(\mathrm{SD} 345)$ & 393 & 546 & 0.19 & 17.0 \\
\hline $\mathrm{D} 13(\mathrm{SD} 295 \mathrm{~A})$ & 379 & 530 & 0.18 & 18.2 \\
\hline $\mathrm{D} 13(\mathrm{SD} 345)$ & 375 & 565 & 0.18 & 16.7 \\
\hline $\mathrm{D} 19(\mathrm{SD} 345)$ & 394 & 568 & 0.19 & 18.2 \\
\hline
\end{tabular}

\begin{tabular}{c|c|c|c|l}
\hline (b) Concrete & $\begin{array}{c}\text { Compressive } \\
\text { strength }\end{array}$ & $\begin{array}{c}\text { Tensile } \\
\text { strength } \\
\mathrm{N} / \mathrm{mm}^{2}\end{array}$ & $\begin{array}{c}\text { Strain at } \\
\text { comp. str. } \\
\% m^{2}\end{array}$ & $\begin{array}{l}\text { Young's } \\
\text { modulus * } \\
\times 10^{3} \mathrm{~N} / \mathrm{mm}^{2}\end{array}$ \\
\hline SpecimenK2 & 50.5 & 3.4 & 0.23 & 31.1 \\
\hline SpecimenK3 & 52.2 & 4.1 & 0.23 & 31.8 \\
\hline
\end{tabular}

* Secant modulus at one-third of compressive strength

Values within parentheses: Column-to-beam flexural strength ratio

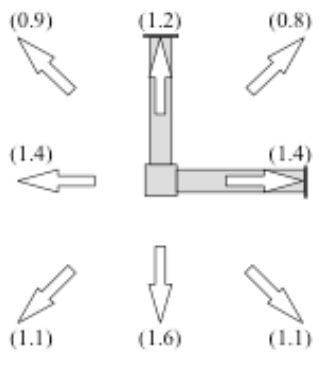

a) Specimen $\mathrm{K} 2$

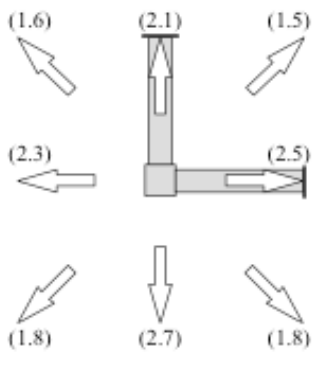

b) Specimen K3

Figure 4: Column-to-beam flexural strength ratio under loading direction pointed by arrows.

$b_{\mathrm{j}}$ : effective width of a joint provided by following equation;

$b_{j}=b_{b}+b_{a 1}+b_{a 2}$

where $b_{\mathrm{b}}$ : beam width, $b_{\mathrm{a} 1}$ and $b_{\mathrm{a} 2}:$ the smaller of one-quarter of column depth $(D / 4)$ and one-half of the distance between beam and column faces on either side of beam $\left(b_{\mathrm{i}} / 2\right), D$ is column depth, and $D_{\mathrm{j}}$ : column depth for an interior joint, or horizontally projected length of anchored beam bars for exterior and knee joints. 


\section{Loading Apparatus and Instrumentation}

The loading apparatus in the south elevation is shown in Figure 5. The east elevation was almost same as Figure 5. Beam ends were supported by horizontal rollers, while a bottom of the column was supported by a universal joint. The reversed cyclic horizontal load and the constant axial load were applied at the top of the column through a tri-directional joint by three oil jacks. Rotation around a vertical axis in the column was prevented by a steel pantagraph placed in a horizontal plane. Specimens were controlled by a story drift angle for loading cycles of $0.25 \%, 0.5 \%, 1 \%, 1.5 \%, 2 \%, 3$ $\%$ and $4 \%$. The story drift angle was defined as a story drift divided by a height of the column, $2400 \mathrm{~mm}$.

Loading paths at the top of the column under bi-directional lateral load reversals are shown in Figure 6. The top of the column moves in a square path in the horizontal plane. For the first loading cycle, after a prescribed drift was given to the top of the column from the origin point $\mathrm{O}$ to point $\mathrm{A}$ in Figure 6 (a), the loading path was defined by a counterclockwise square from points A to I, and finally the column top was loaded back to the origin point $\mathrm{O}$. For the second loading cycle, the loading path was a clockwise square from points $\mathrm{J}$ to R in Figure 6 (b). For all bi-directional lateral loading cycles, uni-directional lateral load was applied until the prescribed drift was achieved in one direction, then, holding the drift constant in that direction, loading was applied in the other direction.

Lateral forces, column axial load and beam shear forces were measured by load-cells. Story drift, beam and column deflections, and local displacement of a beam-column joint were measured by displacement transducers. Strains of beam and column longitudinal bars and joint hoops were measured by strain gauges.

\section{TEST RESULTS}

\section{General Observations}

Crack patterns and damage conditions on the south surface of the joint are shown in Figure 7 at story drift angles of $1 \%$ and $2 \%$. Flexural cracks occurred at beam critical sections for the two specimens at a story drift angle of $0.2 \%$. Principal diagonal cracks occurred in the beam-column joint, and beam longitudinal bars and joint lateral hoops yielded during a loading cycle with a story drift angle of $1 \%$ for both specimens. Column longitudinal bars yielded at a story drift angle of $0.9 \%$ for Specimen K2 with a column axial stress ratio of 0.04 and $1.5 \%$ for Specimen K3 with a column axial stress ratio of 0.12 . Almost all longitudinal bars in the beams and column yielded at both the vertical or horizontal critical section and a point crossing a short diagonal crack which developed from a reentrant corner shown in Figure 1.

Damage in a joint panel for Specimen K3 with a column axial stress ratio of 0.12 was mitigated up to a story drift angle of $1.5 \%$ compared to Specimen K2 with a column axial stress ratio of 0.04 , but progressed abruptly during a loading cycle with a story drift angle of $2 \%$. Core concrete in the joint region spalled off, and column longitudinal bars buckled within the joint at a story drift angle of $3 \%$ for Specimen K2 and $2 \%$ for Specimen K3. Column bar buckling was caused by concrete crushing in the beam-column joint core and inferior confining action due to the small number of joint lateral hoops and column longitudinal bars.

Judging from these observations and the fact that the peak lateral-load carrying capacity did not attain to the ultimate shear capacity of a beam-column joint obtained by AIJ provisions, the joints in both specimens failed as a result of joint hinging as opposed to joint shear. Beam ultimate flexural capacity for Specimen K3 was, however, at first developed at column faces as mentioned later.

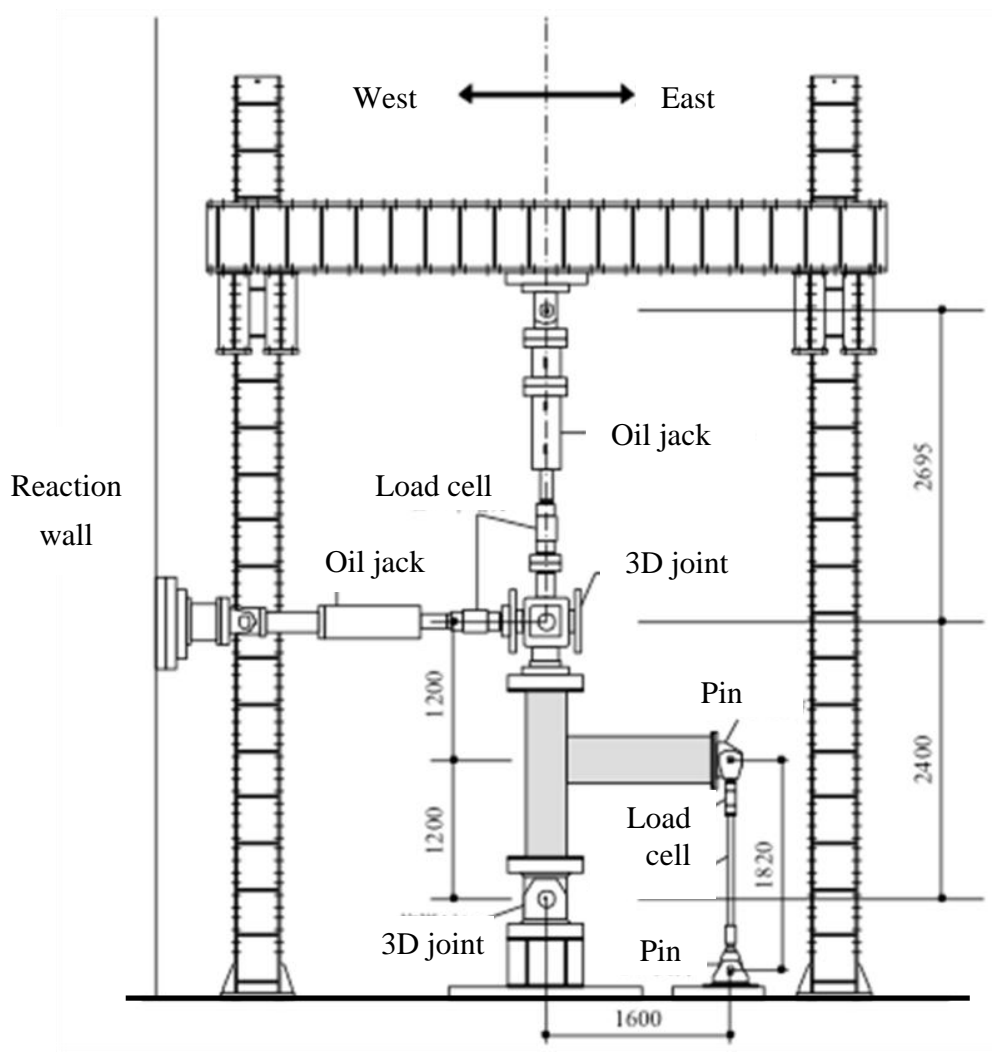

Figure 5: Loading apparatus. (a) First loading cycle

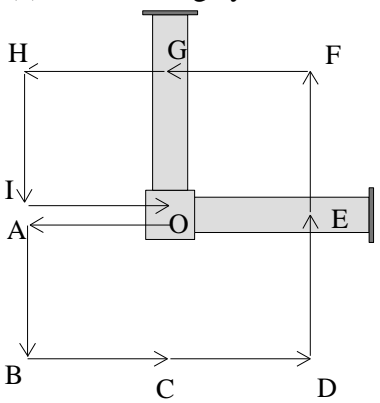

North

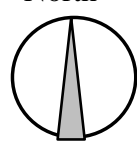

(b) Second loading cycle

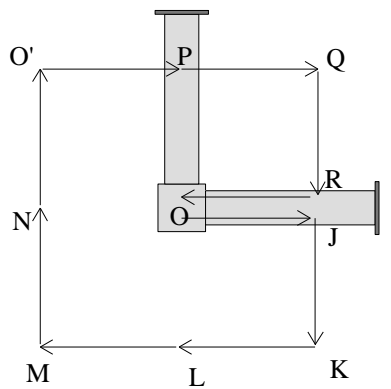

Figure 6: Loading paths at top of column. 


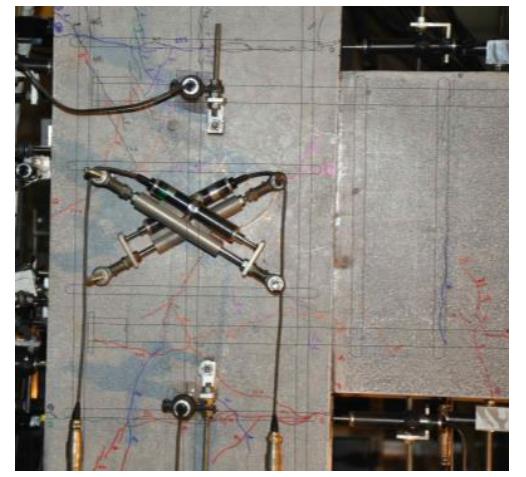

(a-1) Specimen K2
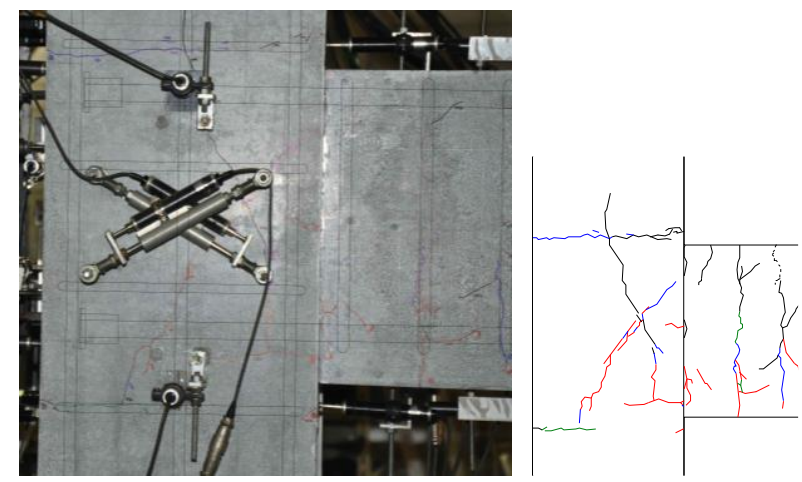

(a-2) Specimen K3

(a) Crack patterns at story drift angle of $1 \%$

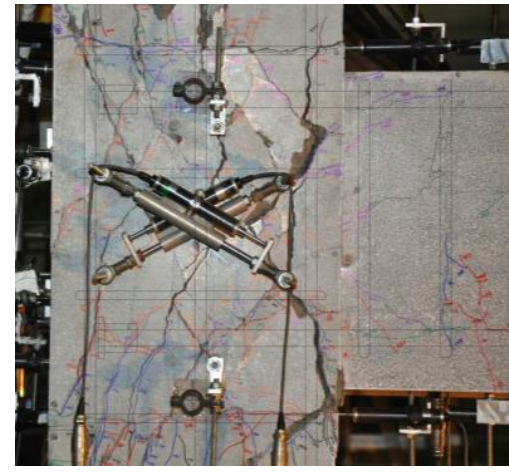

(b-1) Specimen K2

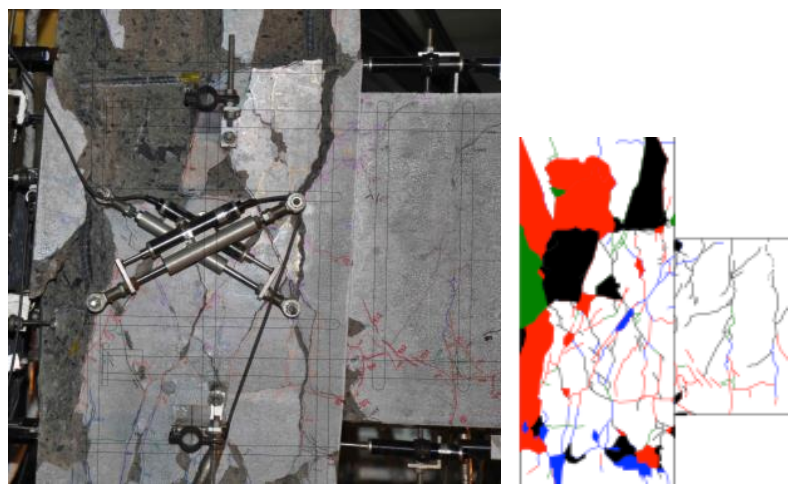

(b-2) Specimen K3

(b) Crack patterns at story drift angle of $2 \%$

Figure 7: Crack patterns and damage conditions.

Damage in a beam-column joint surface without framing beams was heavier than that with framing beams as shown in Figure 8. This indicates that beams framing into a joint panel contributed to mitigating damage to the joint due to its confining action.

\section{Relationship between Story Shear and Drift}

The story shear force - story drift relations are shown in Figure 9 in the east-west and north-south directions. The story shear force was computed from moment equilibrium between the measured beam shear force and the horizontal force at the loading point at the top of the column. Peak story shear forces and story drift angles when reaching the peak story shear force obtained by the tests are summarized in Table 3 along with predicted ultimate capacities of the beam and joint. The ultimate beam flexural capacity, computed by a section analysis assuming that plane sections remain plane, is indicated by a horizontal solid line in Figure 9. The joint hinging capacity was evaluated according to a proposed method by Kusuhara and Shiohara [2] based on the failure mechanics in a beam-column joint shown in Figure 1, indicated by a horizontal dotted line in Figure 9 and Table 1 . The joint hinging capacity is computed by using the columnto-beam flexural strength ratio, the amount and yield strength of joint lateral hoops and beam longitudinal bars, concrete compressive strength and an aspect ratio of the joint region.

One hysteresis loop in the east-west direction during a first loading cycle at a story drift angle of $1 \%$ is highlighted in Figure 10 for Specimen K2. From loading point A to B, and D to F, lateral load was simultaneously applied in the northsouth direction, while story drift in the east-west direction was kept constant, i.e., a story drift angle of $1 \%$. Lateral shear force descended from loading point $\mathrm{A}$ to $\mathrm{B}$, and $\mathrm{D}$ to $\mathrm{F}$ due to bi-axial interaction for joint hinging resistance.

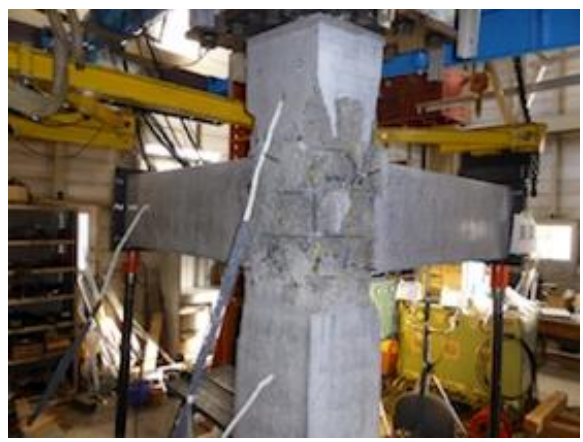

(a) Outer surface

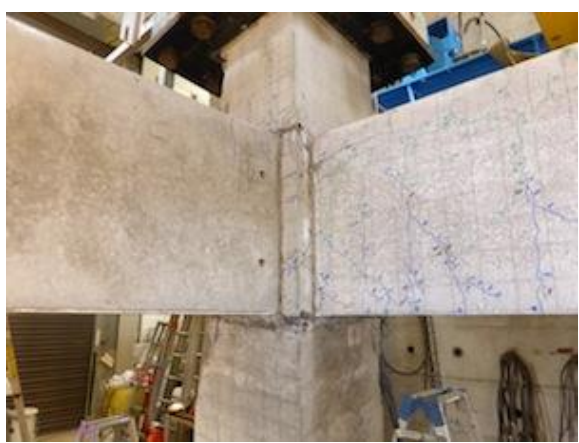

(b) Inner surface

Figure 8: Damage conditions for Specimen K3. 

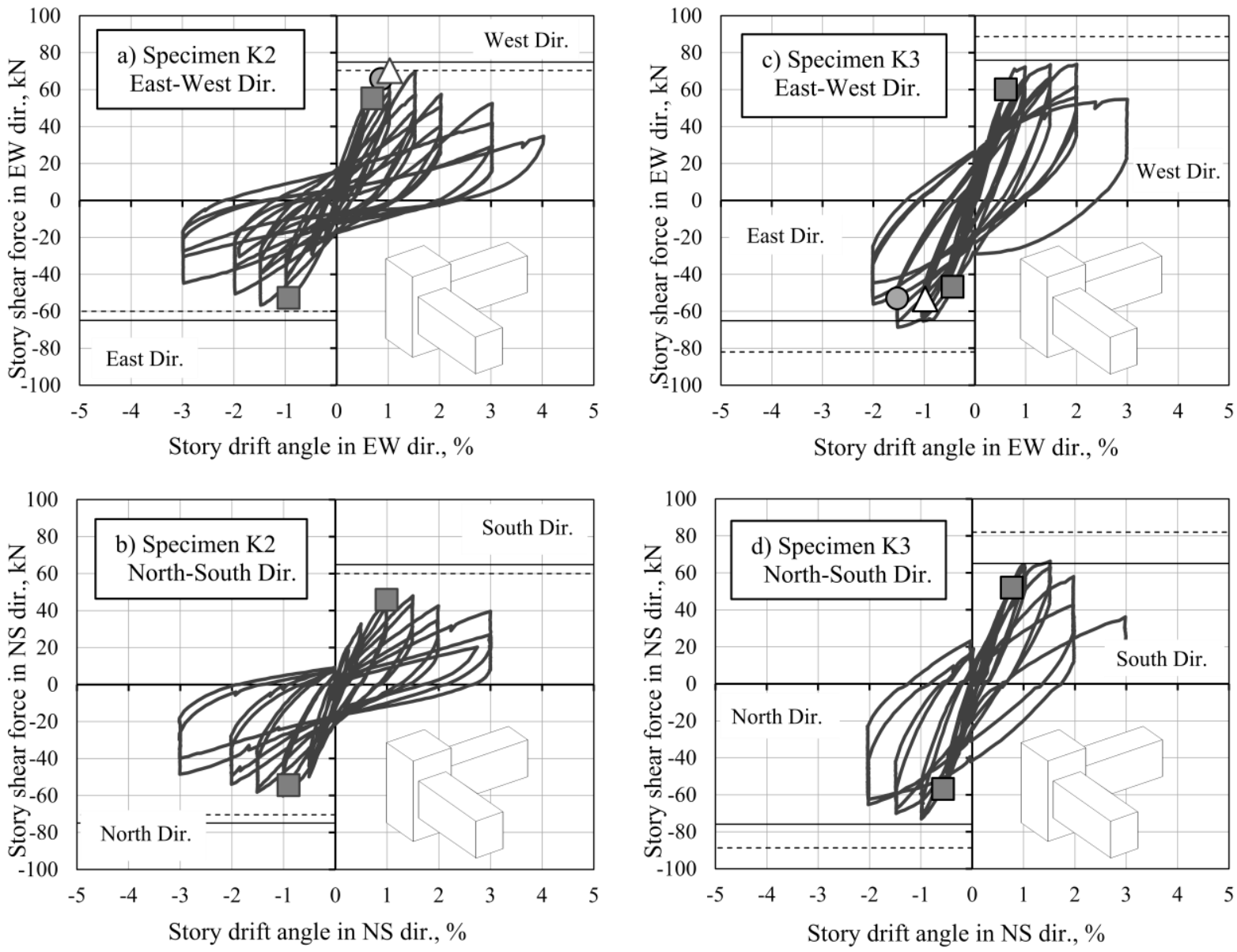

- Beam bar yielding, • Column bar yielding, $\Delta$ Joint hoop yielding

Predicted ultimate beam flexural capacity, - - - - - - Predicted joint hinging capacity

Figure 9: Story shear force - story drift angle relations.

Table 3: Peak story shear forces and story drift angles at peak story shear force.

\begin{tabular}{|c|c|c|c|c|}
\hline \multicolumn{3}{|c|}{ Specimen } & $\mathrm{K} 2$ & K3 \\
\hline \multirow{4}{*}{$\begin{array}{l}\text { Peak story shear force } \\
\text { obtained by tests, kN }\end{array}$} & \multirow{2}{*}{ EW direction } & Positive loading & $70.3(1.03 \%)$ & $73.7(2.00 \%)$ \\
\hline & & Negative loading & $56.6(1.48 \%)$ & $68.6(1.52 \%)$ \\
\hline & \multirow{2}{*}{ NS direction } & Positive loading & $48.0(1.50 \%)$ & $66.3(1.52 \%)$ \\
\hline & & Negative loading & $60.2(1.01 \%)$ & $73.1(0.99 \%)$ \\
\hline \multirow{4}{*}{$\begin{array}{l}\text { Story shear force at } \\
\text { predicted ultimate beam } \\
\text { flexural capacity, } \mathrm{kN}\end{array}$} & \multirow{2}{*}{ EW direction } & Positive loading & 74.9 & 75.9 \\
\hline & & Negative loading & 64.9 & 65.1 \\
\hline & \multirow{2}{*}{ NS direction } & Positive loading & 64.9 & 65.1 \\
\hline & & Negative loading & 74.9 & 75.9 \\
\hline \multirow{4}{*}{$\begin{array}{l}\text { Story shear force at } \\
\text { predicted joint hinging } \\
\text { capacity, kN }\end{array}$} & \multirow{2}{*}{ EW direction } & Positive loading & 70.4 & 88.7 \\
\hline & & Negative loading & 60.0 & 82.0 \\
\hline & \multirow{2}{*}{ NS direction } & Positive loading & 60.0 & 82.0 \\
\hline & & Negative loading & 70.4 & 88.7 \\
\hline \multicolumn{3}{|c|}{$\begin{array}{l}\text { Story shear force at predicted ultimate joint shear capacity in NS } \\
\text { direction, } \mathrm{kN}\end{array}$} & 117.1 & 119.9 \\
\hline
\end{tabular}

* A number in parentheses means a story drift angle in unit of $\%$ at peak story shear force.

Hysteresis loops exhibited a little pinching shape for Specimen K2 with a column axial stress ratio of 0.04 (a column-to-beam flexural strength ratio of 1.4). In contrast, those showed a fat spindle shape for Specimen K3 with a column axial stress ratio of 0.12 (a column-to-beam strength ratio of 2.3), showing a larger amount of energy dissipation. This was caused by restraint of diagonal crack opening in a joint due to large column axial load in Specimen K3. 


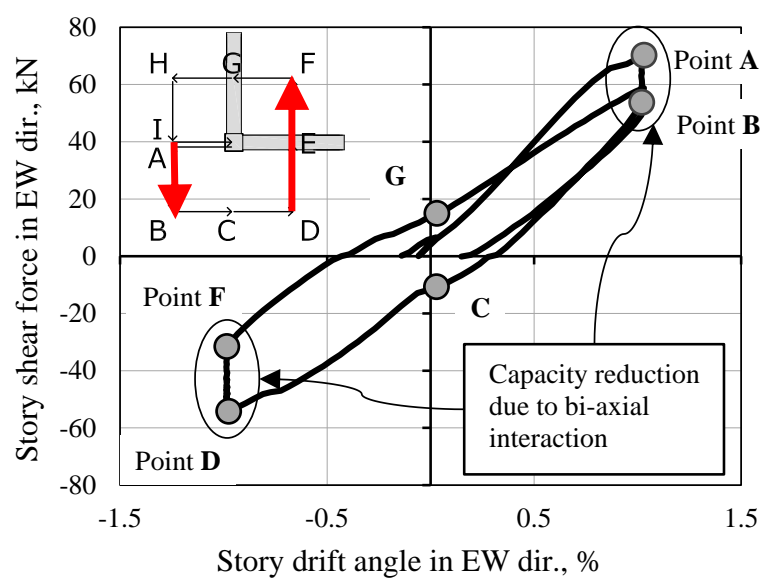

Figure 10: Hysteresis loop in EW direction during first loading cycle at story drift angle of $1 \%$ (Specimen K2).

Peak story shear capacity in uni-directional loading toward the west direction was $6 \%$ lower than the predicted ultimate beam flexural capacity, but reached the joint hinging capacity for Specimen K2. Peak story shear capacity during bi-directional loading in the north-south direction, however, did not reach even the joint hinging capacity, being $20 \%$ or $26 \%$ lower than the joint hinging capacity or the ultimate beam flexural capacity respectively. This resulted from joint hinging failure under bi-directional loading, where the orbit of the story shear resistance depicted an elliptical curve on a coordinate surface of the EW-NS direction story shear forces as mentioned later (refer to Figure 14). The story shear capacity for Specimen K2 decreased by $25 \%$ at a story drift angle of $3 \%$ due to concrete crushing and column bar buckling within a joint region.

Peak story shear capacity during uni- or bi-directional loading for Specimen K3 attained to 0.96 to 1.05 times the predicted ultimate beam flexural capacity. This indicates that the beams developed nearly their full flexural capacity even during bidirectional loading. Damage concentrated in the joint region after loading to point B in Figure 6 at a story drift angle of 2 $\%$, resulting in severe crushing of joint core concrete and column bar buckling. Vertical axial deformation in the joint begun to shorten during the loading cycle with a story drift angle of $3 \%$ indicating a loss of axial load capacity. Thus the test for Specimen K3 was terminated at this point.

\section{DISCUSSIONS}

\section{Diagonal Crack Width in Joint}

Widths of a principal diagonal crack along a main compression strut in a joint are shown in Figure 11. The widths were measured by a crack-gauge under bi-directional loading at a story drift angle of $2 \%$ located at both loading point $\mathrm{F}$ and point $\mathrm{G}$ at an $\mathrm{EW}$ directional story drift of zero as shown in Figure 6 (a). Note that a NS directional story drift was kept constant for loading from point $F$ to $G$, sustaining some story shear force in the north-south direction. Locations where crack widths were measured are shown in Figure 12; a principal diagonal crack crosses a center axis of the column at point "a" and crosses another diagonal crack generated by a reversed loading at point "b".

The maximum crack width for Specimen K3 was $0.75 \mathrm{~mm}$ at loading point $F$ subjected to peak story shear force in the eastwest direction at the measurement point "a", which was onequarter that of $3 \mathrm{~mm}$ for Specimen K2. Crack widths measured for Specimen K3 were consistently smaller than crack widths measured for Specimen K2 for a range of loading points. This

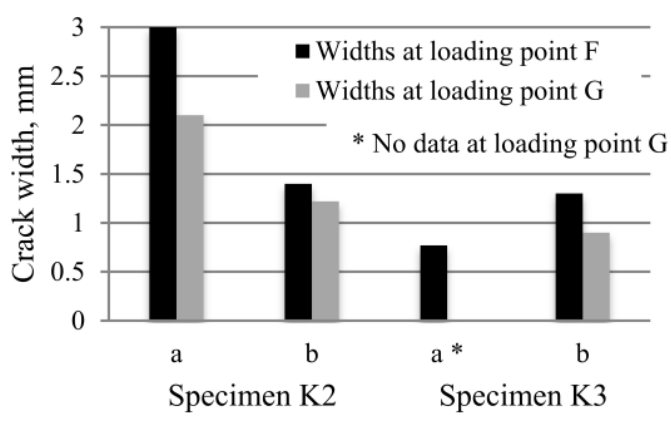

Figure 11: Principal diagonal crack widths in joint.

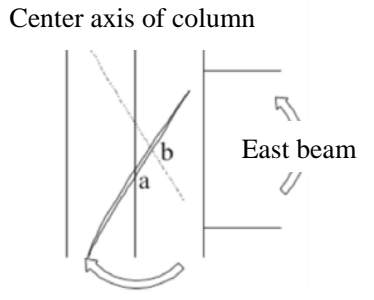

Figure 12: Measuring points of diagonal crack width.

confinement of crack opening is attributed to compressive axial load to the column in Specimen K3 which was three times as large as that in Specimen K2.

\section{Stress Flow from Beam Bar to Concrete in Joint}

Compressive stress induced in the concrete of a corner beamcolumn subassemblage flows as shown in Figure 1. Compressive force from the upper column goes towards anchorage plates of beam longitudinal bars in the joint, and the direction of the force changes at the anchorage plates due to a horizontal compressive reaction derived from beam bar tensile force, forming a diagonal compressive strut in the joint concrete. Thus the beam bar tensile force is carried to the joint concrete through both bond action along beam bars and bearing compressive action of anchorage plates placed at the end of beam bars. Beam bar tensile force (indicated by open squares), bond force (solid circles) and bearing compressive force at anchorage plates (solid diamond-shapes) are shown with a story drift angle in Figure 13 at loading point A during uni-directional loading in Figure 6 (a). The beam bar tensile force was obtained from measured strain at the column face in Figure 13 (c). Bearing compressive force at anchorage plates was regarded as equal to beam bar tensile force at the nearest strain-measuring point to the plate. Bond force along a beam bar was taken as a difference between the beam bar tensile force and the bearing compressive force.

For Specimen K2 with a column axial stress ratio of 0.04 , the bond force reached the peak at a story drift angle of $0.5 \%$. The bond force descended with an increase in a story drift, and finally disappeared at a story drift angle of $1.5 \%$. Hereafter, the beam bar tensile force was carried to the joint concrete by only the bearing compressive force. In contrast, a residual bond force of $20 \mathrm{kN}$ was recorded for Specimen K3 (with a column axial load three times as large as Specimen K2) even at a story drift angle of $2 \%$. At a story drift angle of $3 \%$, when horizontal load-carrying capacity descended remarkably for Specimen K3, almost all beam bar tensile force was introduced into joint concrete by bearing compressive force. 


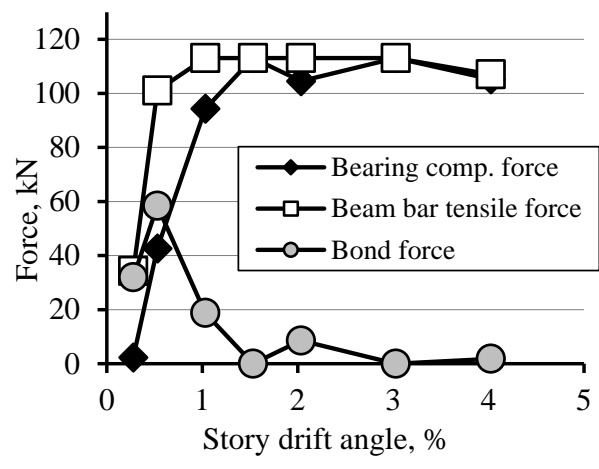

(a) Specimen K2

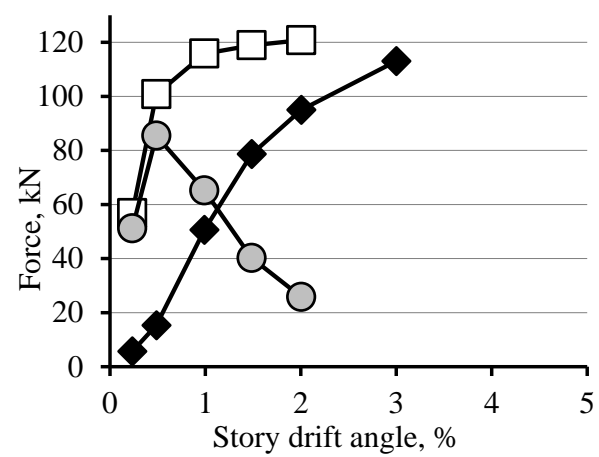

(b) Specimen K3

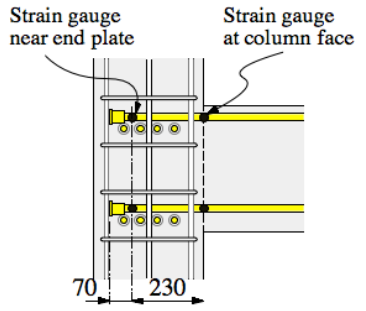

(c) Location of strain gauges

Figure 13: Beam tensile force, bond force and bearing compressive force at anchorage plate in joint.

\section{Biaxial Interaction of Story Shear Resistance}

The orbit of the story shear resistance under bi-directional lateral loading in the first loading cycle is shown in Figure 14 at a story drift angle of $0.5 \%$ before the occurrence of diagonal cracks in a joint, $1 \%$ at diagonal cracking in a joint and $2 \%$ at concrete crushing in a joint. The ultimate beam flexural capacity, the joint shear capacity, and the joint hinging capacity each predicted by aforementioned methods are also shown in Figure 14. The ultimate flexural capacity of a beam is illustrated by a rectangular surface by broken lines in Figure 14, while the joint shear or joint hinging capacities are indicated by circular or elliptical surfaces respectively. All the orbits of a story shear resistance under bi-directional loading remained inside a circle of the predicted joint shear capacity for both specimens. This indicates that a beamcolumn joint did not fail in shear.

The orbit of a story shear resistance for Specimen K2 depicted a rectangle under bi-directional loading at a story drift angle of $0.5 \%$ since little damage occurred in a beam-column joint. The orbit, however, changed to a curved line at a story drift angle of $1 \%$ because of joint damage. Then four peak points under bi-directional loading, i.e., points $\mathrm{B}, \mathrm{D}, \mathrm{F}$ and $\mathrm{H}$ in Figure 14 (a), were located on the elliptical line of the predicted joint hinging capacity.
The orbit of the story shear resistance for Specimen K3 with a column axial load three times as large as Specimen K2, depicted a rectangular surface under bi-directional loading up to a story drift angle of $1 \%$ (as indicated in Figure 14 (b)) since the joint concrete suffered only slight damage. Peak story shear capacities, especially at loading points B and D in Figure 14 (b), almost reached both the ultimate beam flexural capacity and the joint hinging capacity. Specimen K3 behaved dominantly in beam flexure and then reached the peak capacity because damage was slight in a beam-column joint at a story drift angle of $1 \%$. Just before loading point $\mathrm{F}$ at a story drift angle of $1 \%$, however, the story shear capacity in the east-west direction decreased due to the onset of joint hinging failure, which was attributed to reduction of axial load in the lower column at loading point $\mathrm{F}$ induced by vertical shear forces in both beams. After loading point $\mathrm{F}$, damage to the joint grew rapidly with the continued increase in story drift and the story shear resistance descended. Thus the orbit of a story shear resistance at a story drift angle of $2 \%$ depicted curved lines and was located within the elliptical orbit at a story drift angle of $1 \%$ for Specimen K3.

It is revealed that the ultimate capacity of corner beam-column joints under bi-directional lateral loading can be estimated based on the new mechanism of joint hinging failure proposed by Kusuhara and Shiohara [2].

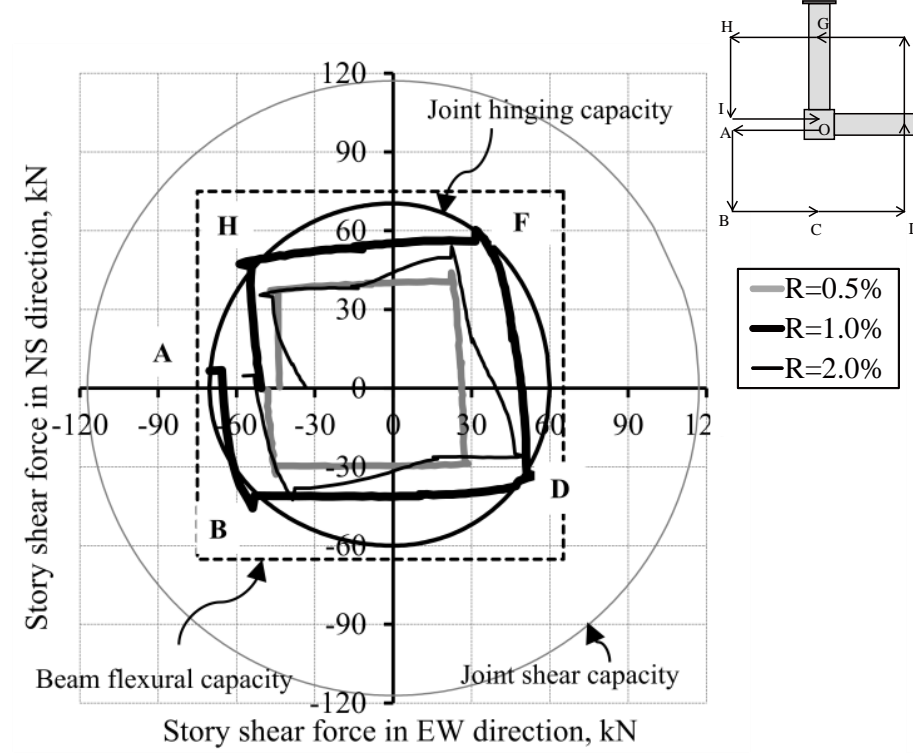

(a) Specimen K2 (Axial Load: $260 \mathrm{kN}$ )

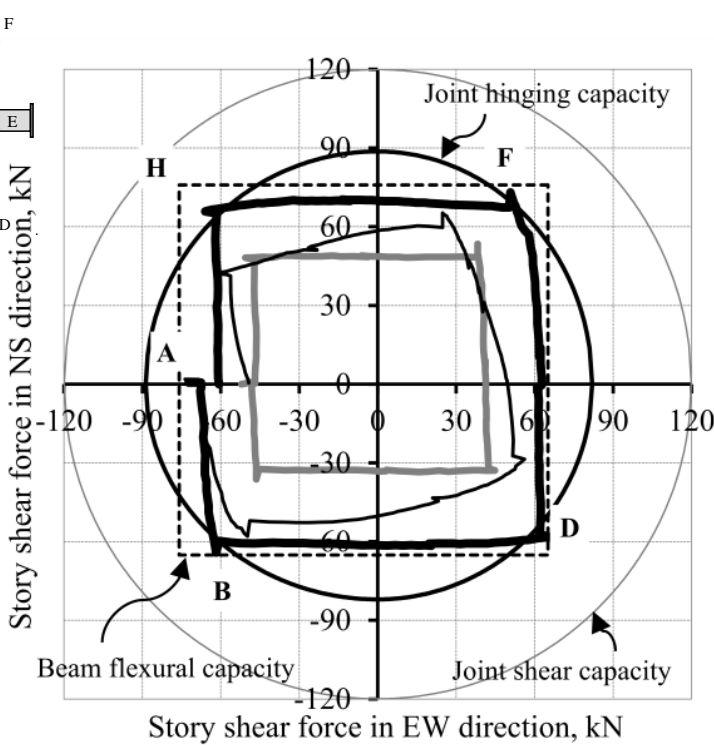

(b) Specimen K3 (Axial Load: $770 \mathrm{kN}$ )

Figure 14: Orbit of story shear resistance under bi-directional loading. 


\section{Story Shear Resultant Force under Bi-directional Lateral Loading}

Envelope curves of the relationship between the story shear resultant force and story drift resultant angle under bidirectional loading from the origin point $\mathrm{O}$ to loading point $\mathrm{C}$ (in the loading paths illustrated in Figure 6) are shown in Figure 15. The story shear resultant force or story drift resultant angle were obtained by the square root of sum of squares of story shear forces or story drift angles in EW and NS directions.

The story shear force at loading point $\mathrm{A}$ reached the peak value of $70.6 \mathrm{kN}$ at a story drift angle of $1 \%$ for Specimen $\mathrm{K} 2$. During bi-directional loading from loading point A to B, a story shear resultant force remained almost constant; $70.6 \mathrm{kN}$ at loading point B in Figure 15 (a). This was caused because the beam-column joint started to fail in joint hinging at loading point $\mathrm{A}$ and the orbit of the story shear resistance under bi-directional loading depicted part of an ellipse as shown in Figure 14 (a).

In contrast, flexural yielding for Specimen K3 occurred in an east beam at a story drift angle of $0.8 \%$ and stiffness was degraded as shown in Figure 15 (b). Under bi-directional loading from loading point $\mathrm{A}$ to $\mathrm{B}$, a north beam yielded in flexure and the story shear resultant force increased to $89.0 \mathrm{kN}$ at loading point $\mathrm{B}$, which was $23 \%$ larger than that at loading point $\mathrm{A} ; 72.3 \mathrm{kN}$.

The peak story shear resultant force obtained at loading point $\mathrm{B}$ exceeded the predicted joint hinging capacity, shown by horizontal dashed lines in Figure 15, for both specimens; the former was $8 \%$ or $4 \%$ larger than the latter for Specimen K2 or K3 respectively. The story shear resultant force for Specimen K3 declined heavily due to progressive failure in the beam-column joint after a story drift resultant angle of $2.8 \%$, leading to axial collapse of the subassemblage. This should be noted for seismic design of RC buildings when a small amount of column longitudinal bars and joint lateral hoops are provided accroding to the lower bound required by Japanese building law or seismic provisions.

\section{CONCLUSIONS}

General findings taken from the study are summarized as follows.

(1) Although a joint shear capacity margin of 1.6 estimated by AIJ seismic provisions was provided to a corner beamcolumn joint in the test to prevent shear failure, all joints failed by joint hinging under bi-directional lateral cyclic loading after beam and column longitudinal bars and joint hoops yielded.

(2) Bond force along the longitudinal bars in the beam anchored mechanically into the joint by steel end plates

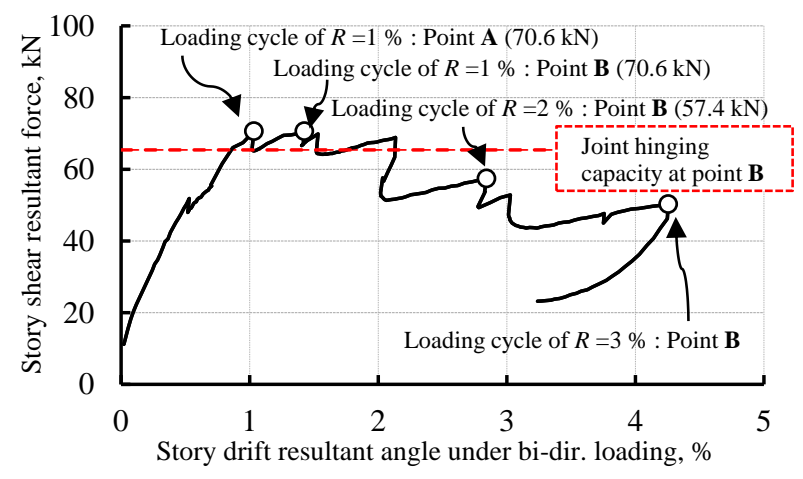

(a) Specimen K2 (Axial Load: $260 \mathrm{kN}$ ) disappeared within the joint before and after peak story shear, i.e., at a story drift angle of $1.5 \%$ for a column axial stress ratio of 0.04 and $3 \%$ for that of 0.12 . When the beam-column joint eventually failed due to joint hinging, beam bar tensile force at the column face was carried to the joint core concrete through bearing compressive force at the end plates.

(3) Peak story shear force in the transverse direction under bidirectional loading was 0.74 times the ultimate beam flexural capacity computed by a section analysis for a corner beam-column subassemblage with a column axial stress ratio of 0.04 (corresponding to a column-to-beam flexural strength ratio of 1.4). In this case, beams did not fully develop their flexural capacity due to joint hinging failure. In contrast, peak story shear force under bidirectional loading almost attained to the ultimate beam flexural capacity for a subassemblage with a column axial stress ratio of 0.12 (corresponding to a column-to-beam flexural strength ratio of 2.3), whereas lateral-load carrying capacity descended severely after the peak capacity, attributed to severe damage in a joint region.

(4) When the column compressive axial load was increased from an axial stress ratio of 0.04 to 0.12 , the ultimate joint hinging capacity for the corner joint computed as a resultant force of two orthogonal story shear forces under bi-directional lateral loading was enhanced by 1.2 to 1.4 times as a result of the large column axial load. The joint hinging capacity with an axial stress ratio of 0.12 , however, decreased heavily after the peak capacity, leading to axial collapse of the subassemblage. This should be noted for seismic design to RC buildings when a small amount of column longitudinal bars and joint lateral hoops are provided according to the lower bound required by Japanese building law or seismic provisions.

(5) The ultimate capacity of a corner beam-column joint under bi-directional lateral loading can be estimated based on the new mechanism of joint hinging proposed by Kusuhara and Shiohara [2].

(6) Fatter hysteresis loops were observed under bi-directional lateral loading for the corner beam-column subassemblage specimen with a column compressive axial stress ratio of 0.12 than that of 0.04 , showing a larger amount of energy dissipation. This was caused by restraint of diagonal crack opening in a joint due to large column axial load.

\section{ACKNOWLEDGEMENTS}

The study described herein was sponsored by the Grant-in-aid for Scientific Research (B) of Japan Society for the Promotion of Science (Principal researcher: H. Shiohara, professor of the University of Tokyo, Japan). Authors would like to express their gratitude to Prof. Shiohara for his valuable advice, Dr. T. Endo, former assistant professor of Tokyo Metropolitan

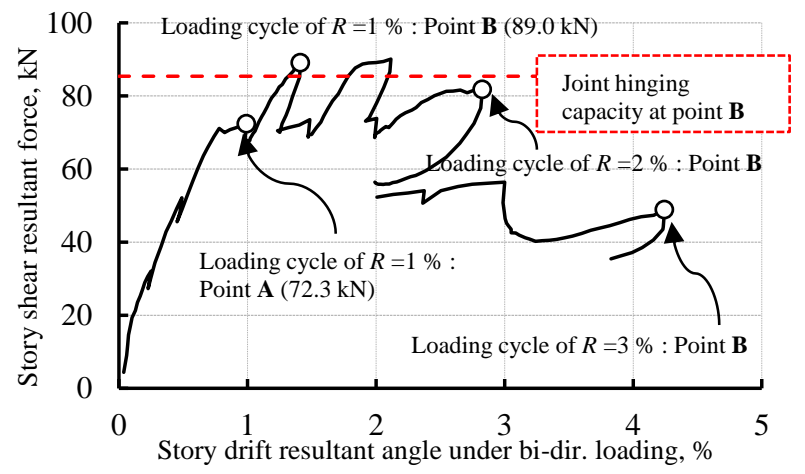

(b) Specimen K3 (Axial Load: $770 \mathrm{kN}$ )

Figure 15: Story shear resultant force under bi-directional loading. 
University, for his assistance in conducting the tests and Tokyo Tekko Co. Ltd. for providing steel bars.

\section{REFERENCES}

1 Shiohara H (2001). "New model for shear failure of RC interior beam-column connections". Journal of Structural Engineering, 127(2): 152-160.

2 Kusuhara F and Shiohara H (2013). "Ultimate moment of reinforced concrete exterior beam-column joint". Journal of Structural and Construction Engineering, 78(693): 1949-1958.

3 Ishiki $\mathrm{K}$ et al. (2011). "Test for Failure Mechanism of R/C Interior Beam-Column Joint". Summaries of Technical Papers of Annual Meeting of the Architectural Institute of Japan (AIJ), Japan, Structures IV: 497-498 (in Japanese).
4 Suzuki Y et al. (2014). "Effect of Lateral Reinforcement and Axial Force on Structural Performance of Exterior Beam-Column Joints in Reinforced Concrete Buildings Part 1, 2 and 3". Summaries of Technical Papers of Annual Meeting of the Architectural Institute of Japan (AIJ), Japan, Structures IV: 361-366 (in Japanese).

5 Nishimura K, Muraoka S, Yagiura T and Onishi N (2014). "An experimental study on stress transfer in a reinforced concrete corner beam-column joint yielded in flexure at beam ends". Journal of Structural and Construction Engineering, 79(699): 621-630.

6 Architectural Institute of Japan (1999). "Design Guidelines for Earthquake Resistant Reinforced Concrete Buildings Based on Inelastic Displacement Concept". Architectural Institute of Japan (AIJ), Japan. 